\title{
The strange quiet of things misplaced: Craft, material and memory in the work of Elisa Markes-Young
}

\author{
Belinda von Mengersen
}

\begin{abstract}
This paper will consider the relationship between the performative nature of craft and the transformation of memory, as exemplified in the work of Elisa Markes-Young. Particular reference will be made to her series The strange quiet of things misplaced (2007-2011), which is based on memories of domestic linen from her Eastern European childhood. This discussion offers a provisional reading of the series, relating to the concepts of craft, material and memory, and considers how devices like encounter and mimicry can elicit both memory and improvisational craft practices. Markes-Young, who has no formal training in traditional textile techniques, describes her process as a literal activation of memory through making, giving rise to the question: 'Can the techniques of material practice provide the means for not only creation and reflection, but also an altogether new "encounter" between the artist and her work: occasioning both new works and enriched memories?' Such a proposal contrasts with the popular conception of artists drawing on memory to inspire their artworks: here, it is suggested, memory is encountered, activated, and enhanced by physical and conceptual craft practice.
\end{abstract}

\section{Introduction}

Memory is a mystery. We imagine it as being some sort of a cupboard where things are stored and pulled out when needed. But sometimes things are misplaced and it's only then, when our memory has failed us, that we brood over its nature ... (Markes-Young 2011: 19)

Elisa Markes-Young has been exhibiting extraordinary, abstract, handembroidered textiles regularly since 2002, when she immigrated to Australia with her husband, New Zealand-born photographer Christopher Young. This was not her first such move: at 16, in the early 1980s, Markes-Young and her family left Poland for Germany. Aspects of this complex cross-cultural experience can be seen in her recent series, The strange quiet of things misplaced (2007-2011), an extensive body of work in which Markes-Young focuses on her unique history and the fallibility of personal memory. Her works incorporate drawing on stretched canvases, overlaid with complex yet irregular handworked net-like stitching. This needlecraft does not follow regular stitching patterns: instead, it mimics them, through a process that is part intuitive, partly dependent on 
recollection. The lace-like incompleteness of these patterns and how they fold back upon themselves disrupts expectations of uniformity. Such tangible irregularities mimic the imperfections and conceptual slippages of memory.

Personal memory and her doubts about its capacity to reproduce clear images of the past that she longs to remember are enduring themes for Markes-Young. This yearning permeates her work, seemingly intensifying her awareness of the 'fragility and fallibility' of memory. Could it be this fallibility that compels the artist to attend to her memory through the daily practice of needlecraft?

In Markes-Young's work there is a complex dependence between material (the threads), craft (the tension which holds them in place) and memory (represented through the use of entropic patterning). This discussion will focus on the dynamic relationship between material, craft and memory within this evocative series.

\section{Encounter and memory}

Encounter: 4. An idea that suddenly presents itself, as it were, by accident; a happy thought. (The Oxford English Dictionary 1989)

Markes-Young describes how she uses craft practice to encounter memory through her series The strange quiet of things misplaced, and how closely aligned this is with her sense of place:

After multiple migrations I don't really belong anywhere and my memories are the closest I have to a home. They - together with the associated fallibility and fragility - form the core of my artistic practice. (2011: 19)

Memory is a shifting site and, for Markes-Young, an encounter with memory is both conceptual (ideas-based) and physical (material or craft practice-based). This discussion of her work focuses on a dialogue between concept and practice and how craft, material and memory pollinate each other. It seems that the unfixed nature of memory operates as a poetic device for the artist, both in her understanding of the enigmatic concepts of memory and her personal migrant history, and also in the way she works with craft techniques and materials. Visually, through a series of net-like images and disrupted pattern structures, Markes-Young's work reflects the workings of memory itself.

Within the visual arts, the term 'encounter' usually relates to the way a viewer perceives a work. This discussion, however, considers the encounter between artist and artwork at the site of investigative, process-based practice. As craft theorist Sue Rowley explains, 'many artists ... invoke craft precisely to reflect critically on questions of ... temporal experience' (2012: 235). Here, perhaps, is a key to the sense of authenticity that radiates from Markes-Young's work. Rowley's words also provide recognition of, and a context for, Markes-Young's need to entertain, to engage with, her own memories. This particular, highly focused craft practice is, in fact, a questioning of her own sense of lived 
experience and also the insecure and fluid nature of her memories. Such encounters seem to offer little comfort: taking the form not of nostalgia, but of rigorous interrogation. The resulting sense of unease may be identified in the following definition of 'encounter':

1. To be faced with something, especially something new, strange, unpleasant, difficult or dangerous;

To meet somebody unexpectedly. (Oxford Advanced Learner's English Dictionary of Current English 1995: 379)

The suggestion of conceptual, metaphorical and physical 'tension' in this word, and its application to an understanding of Markes-Young's series, implies a possibility of transformation and encourages close looking. The concept is not without precedent: visual art theorist Mieke Bal has used 'encounter' to describe an act which takes place during the process of research in the visual arts (2008: 206), linking the concept to both research and imagination. For Markes-Young, then, in whose work the connection between personal research into memory and imaginative making practice is intrinsic, 'encounter' encapsulates an essential, yet uneasy relationship.

\section{Encounter and memory as 'performative paradigm'}

As Estelle Barrett discusses, the dynamic of an encounter, whether physical or 'conversational', can be considered a performative paradigm (2010: 118). Such enunciation has the power to activate thought, and thus memory, in new and sometimes unexpected ways. In Markes-Young's work, the performative meeting of memory, craft and technique enables incipient aspects of understanding, thinking and feeling. And while Barrett uses the concept of 'performative paradigm' to describe creative practice as research, it is also used to contextualise philosopher Julia Kristeva's notion of revolt or transgression - the exact kind of 'revolt' or, in Markes-Young's work, 'encounter' - that is required by creative practice. For Kristeva, such a revolt entails moving from confining language structures and conventions into what she describes as 'poetic' or freeing territories. For Markes-Young, these freeing territories take the form of subverting and adapting formal stitch and design structures taken from memory. The resulting work is at once informed by, and utterly independent of convention. Such an encounter with memory occurs when working with textile materials and craft techniques. And memory itself could be described as a poetic concept of unknowable parameters. It is not a timeline, nor linear, and is therefore not akin to the formality of biography. Within memory, timeframes are displaced and disarranged; shapes only partially visible. For Markes-Young, knowledge of, and encounters with, such shifting territories have become devices which inform both her creative research practice and her pursuit of a sense of 'home'. 


\section{Drawing from memory}

Markes-Young's work in The strange quiet of things misplaced operates outside the conventions of needlecraft practice, using what she calls 'faux' techniques. With no formal training other than a few basic hand-embroidery and crochet stitches learned as a child, Markes-Young has developed her technique in an abstract manner. Her starting point is often a memory: in particular, childhood encounters with traditional Polish textiles gifted to her father, a medical doctor, in lieu of a conventional fee. Rather than revisiting this collection, however, MarkesYoung develops, or 'draws' her own patterns and stitches in an intuitive way in response to images summoned up by memory. With no vocabulary of stitches at her disposal, Markes-Young innovates, employing the childhood learning tool of mimicry: it is as though she imagines how such patterns or techniques should look. The result is that her works mimic, rather than reinterpret, traditional motifs. She references traditional stitch structures and patterns but disrupts their original logical or symmetrical flow. A simulation of traditional needlecraft patterns is thus employed and then disrupted, or extrapolated.

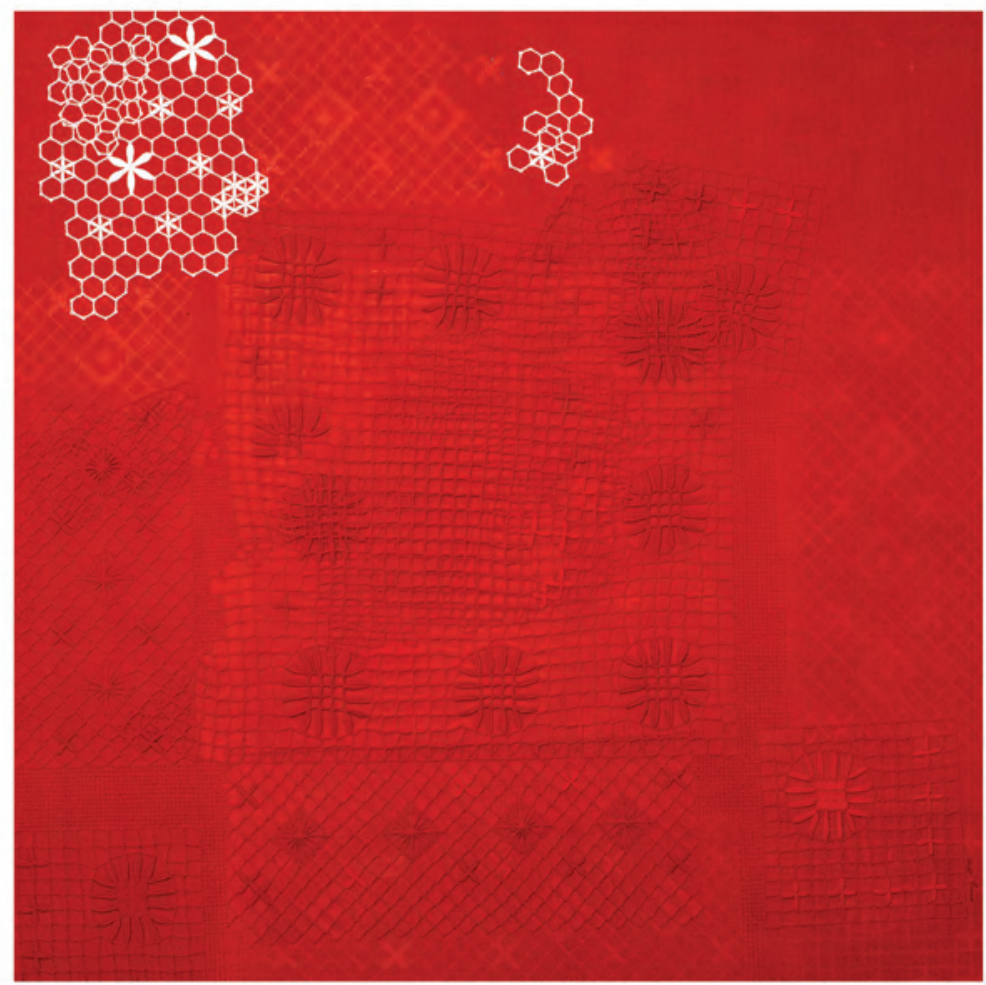

Figure 1. Elisa Markes-Young, The strange quiet of things misplaced \#27, 2011, acrylic, pencil, pastel, wool, cotton and silk on Belgian linen, $1100 \times 1100 \mathrm{~mm}$

Photo: Christopher Young. Licensed by VISCOPY Australia 


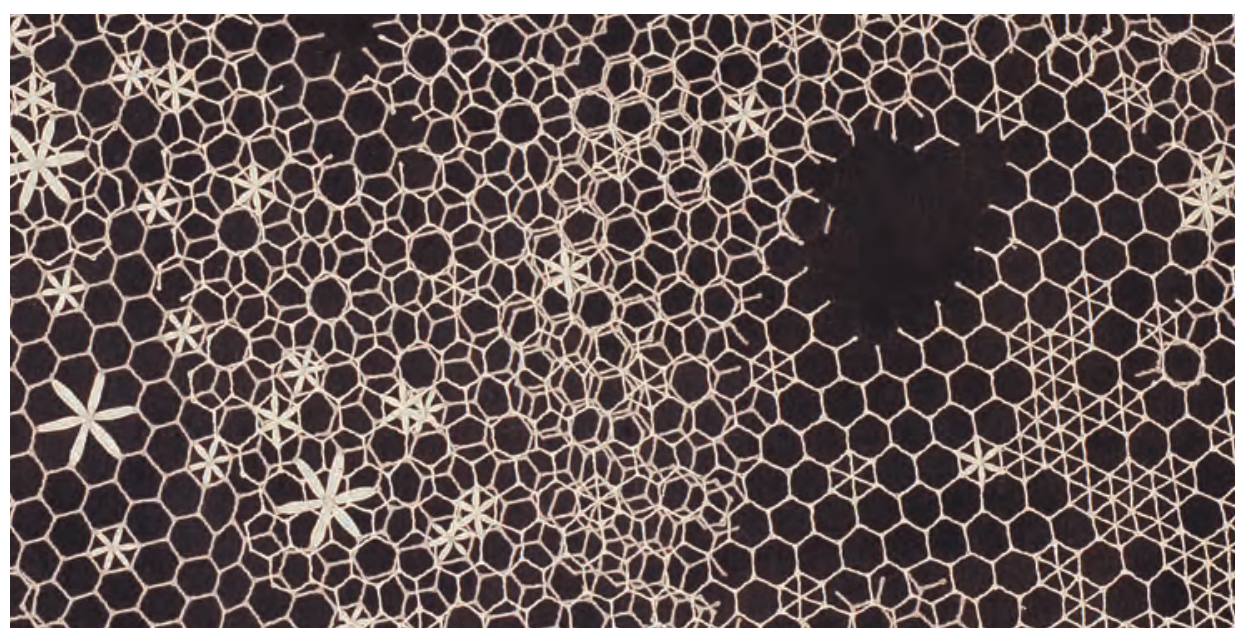

Figure 2. Elisa Markes-Young, The strange quiet of things misplaced \#28, 2010, acrylic, wool, cotton and silk on Belgian linen, $1100 \times 550 \mathrm{~mm}$

Photo: Christopher Young. Licensed by VISCOPY Australia

Working in this way means that, effectively, the patterns used in this series cannot be fully planned, laid out or completed in advance. Instead, this intuitive way of working contributes to the disrupted patterns of the resulting work. These pieces initially appear to contain logical patterns, but on closer inspection the viewer observes their imperfections and deviations. Markes-Young's use of minimal craft techniques and materials in a spontaneous way operates as a form of drawing. Her pseudo patterns within this series are improvisations, resisting conventional order and hinting at erasure and deconstruction. 


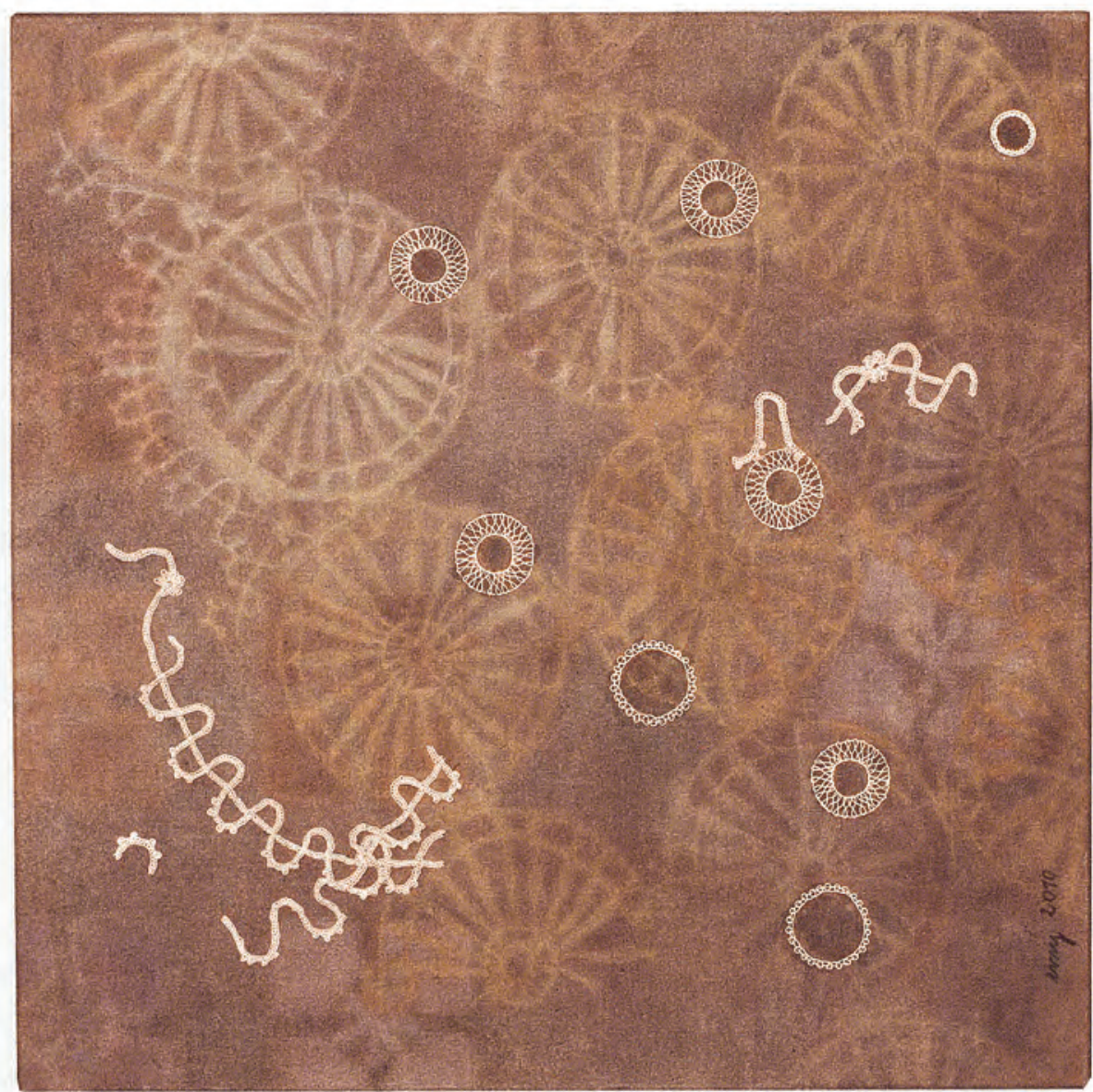

Figure 3. Elisa Markes-Young, The strange quiet of things misplaced \#38, 2010, acrylic, pencil, pastel, wool, cotton and silk on Belgian linen, $550 \times 550 \mathrm{~mm}$

Photo: Christopher Young. Licensed by VISCOPY Australia

In The strange quiet of things misplaced \# 27 (2011) and \#28 (2010) a honeycomb pattern unfolds across the canvas like a net. Initially, this pattern seems obvious, but upon close inspection, the dysfunctional and interrupted qualities are apparent, with net-like shapes overlaid and deconstructed. The entropic breakdown of pattern structure is exaggerated by entwining multiple threads of different weights. The threads are bound against each other like a net structure pinned flat, but they are also independent and multiple, rather than flowing in a continuous line. At certain points stitches have been missed and a hole appears in the net. This is the most obvious sign of a dysfunctional pattern, and demands re-examination. 
These works mimic the conventions of looped net making. In The strange quiet of things misplaced \#27 and \#28, the net form provides a visual metaphor for memory as it is experienced: sections of longed-for logic are distorted, intertwined, overlaid, and 'misplaced'. This is also visible when the tension holding the threads taut gives way and the net changes direction to fold back upon itself. Similarly, \#28 seems to further develop the metaphor: encapsulating Markes-Young's relationship between the visible (created) and invisible (intangible) aspects of memory, and suggesting that, no matter how tightly the 'net' of memory is tensioned, it will almost inevitably yield.

In The strange quiet of things misplaced \#38 (2010) this same tension has riven the work, and, with fragments adrift from the pattern, there is a resulting sense of disruption.

There are often relationships between two or more pieces within this series and they share one number, with The strange quiet of things misplaced \#34 (2010) and \#37 (2011) being examples. In the pair titled \#34, the pattern at first appears to follow the needlecraft convention of symmetry; then it starts to shift and distort. In the second piece, only fragments of the original pattern remain, and these appear to have reconfigured themselves into a new, more organic pattern structure.

In some works within this series, including \#28, \#29, \#30, \#33, \#34, and \#38 (all 2010), this sense of disruption also mimics a basic textile weave structure and how it might be broken down over time by wear. This type of mimicry, another form of the dissolution of pattern, is particularly visible in \#29 through a dissolving grid-like structure. It seems that, in this series, and these examples especially, the use of intuition and the need for mimicry have led to improvisation and innovation. 


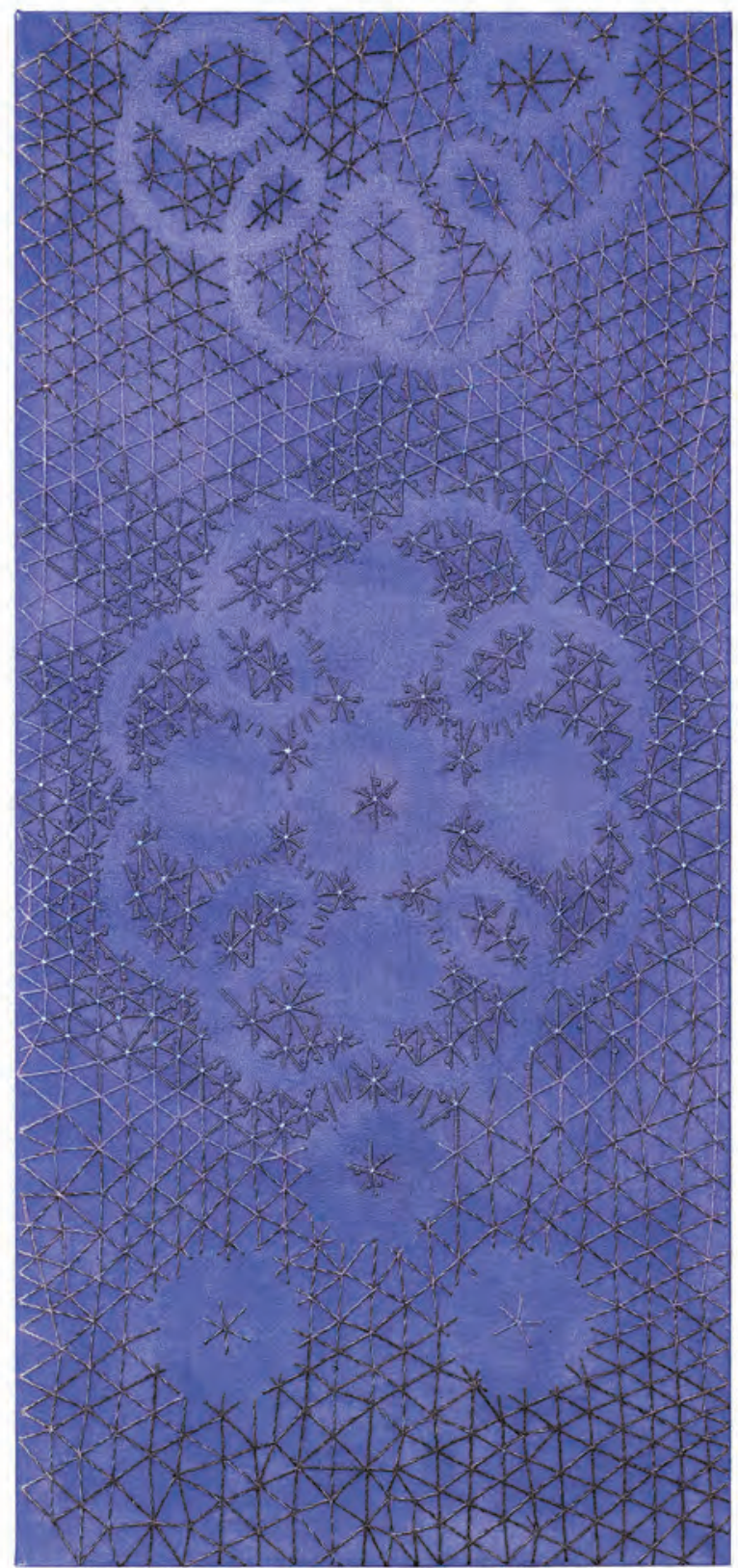

Figure 4. Elisa Markes-Young, The strange quiet of things misplaced \#33, 2010, acrylic, pencil, pastel, wool, cotton and silk on Belgian linen, $550 \times 1100 \mathrm{~mm}$

Photo: Christopher Young. Licensed by VISCOPY Australia 

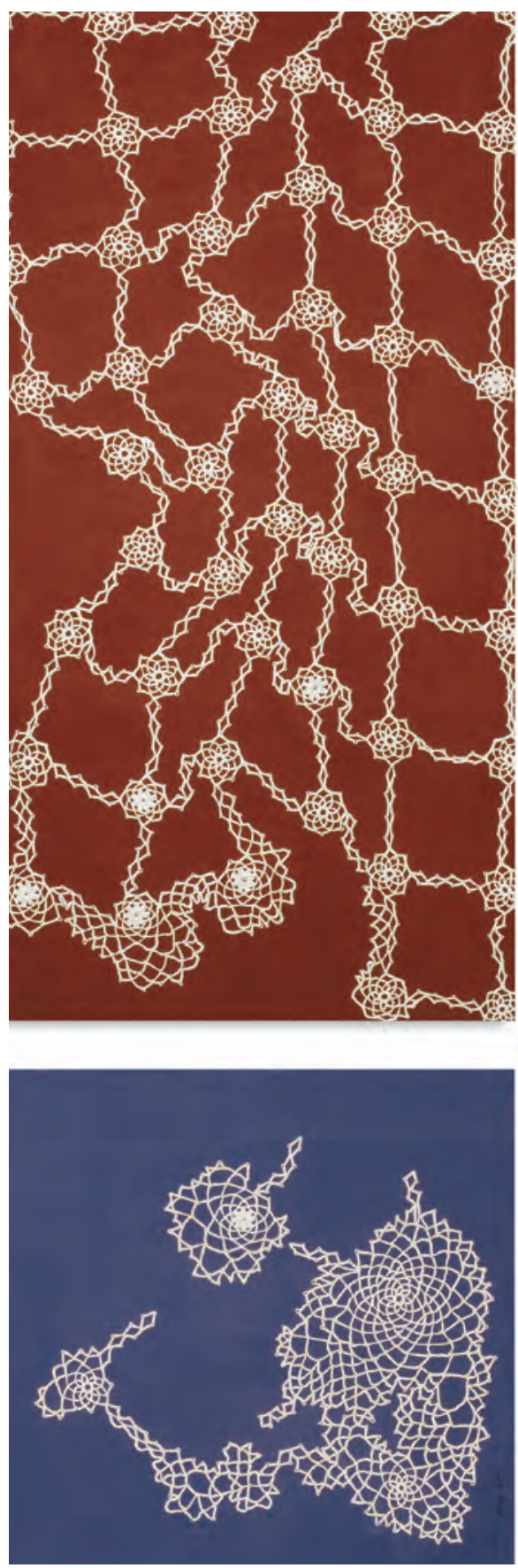

Figure 5. Elisa Markes-Young, The strange quiet of things misplaced \#34, 2010, acrylic, wool, cotton and silk on Belgian linen, two panels, approx. $550 \times 1100 \mathrm{~mm}$ and $550 \mathrm{x}$ $550 \mathrm{~mm}$

Photo: Christopher Young. Licensed by VISCOPY Australia 


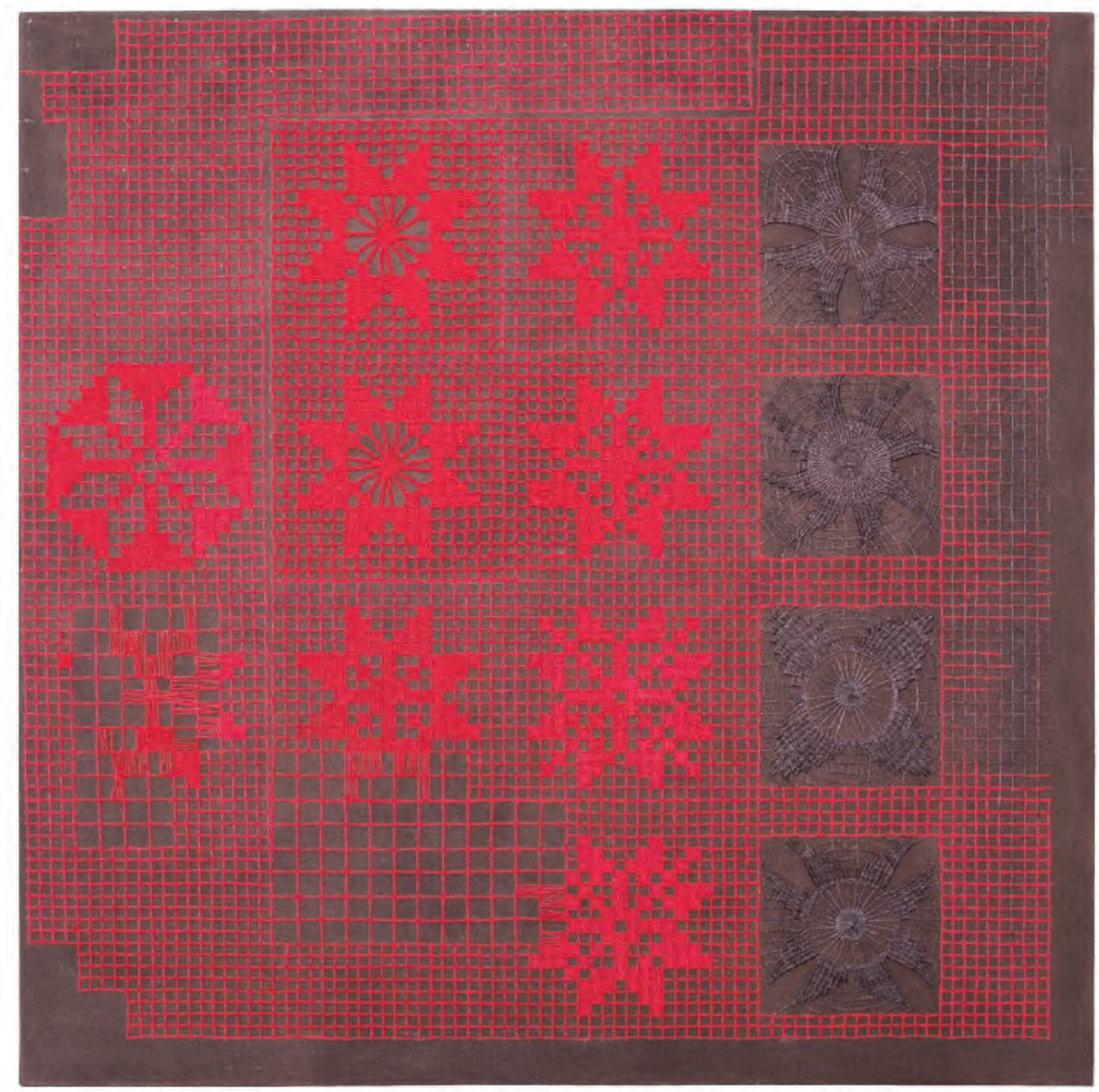

Figure 6. Elisa Markes-Young, The strange quiet of things misplaced \#29, 2010, acrylic, wool, cotton and silk on Belgian linen, $1100 \times 1100 \mathrm{~mm}$

Photo: Christopher Young. Licensed by VISCOPY Australia

Craft and memory can both be read as poetic devices within this work. MarkesYoung mimics and improvises upon traditional craft practices so as to mirror the elusive qualities of memory. The directness of her process, which uses both traditional drawing materials and thread, allows the work to be seen as a performative gesture, bound by improvisation. If poetry can be language freed from itself, as Gaston Bachelard implies (1998), then perhaps 'drawing' such as Markes-Young's can be craft techniques freed from themselves. In the introduction to Air and Dreams: An Essay on the Imagination of Movement, Bachelard considers the restrictions of language in his discussion of a phenomenology of movement: 'language, conditioned by forms, is not readily capable of making the dynamic images of height picturesque' (1998: 10). Bachelard's philosophical process is his attempt to go beyond ascribed limitations of thought and language, as he explains: 
in the realm of imagination transcendence is added to immanence. [Where] going beyond thought is the very law of poetic expression (1998: 5).

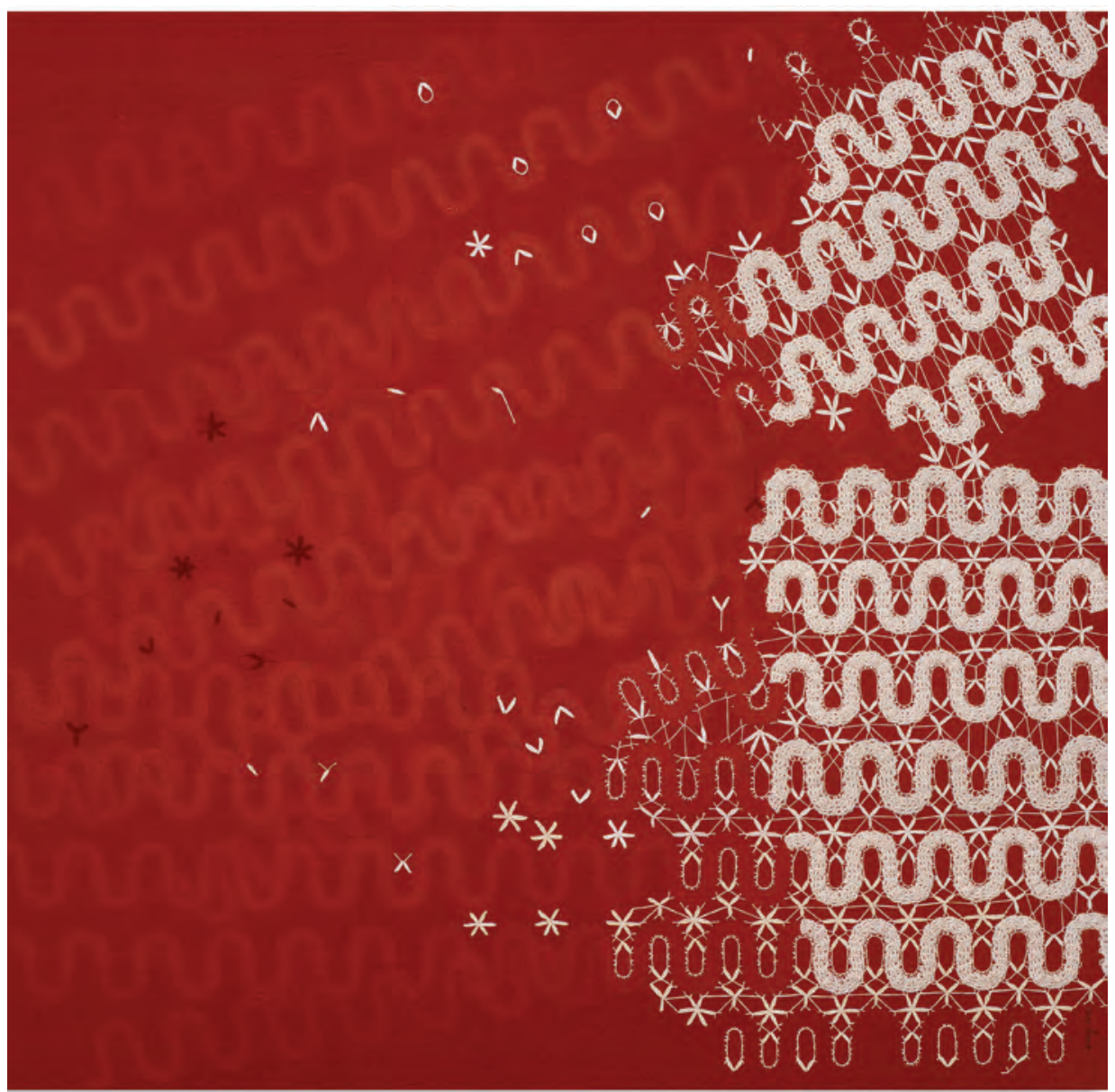

Figure 7. Elisa Markes-Young, The strange quiet of things misplaced \#30, 2010, acrylic, pencil, pastel, wool, cotton and silk on Belgian linen, 1100 x $1100 \mathrm{~mm}$

Photo: Christopher Young. Licensed by VISCOPY Australia

In this series, it would seem that drawing, as a process embedded within conscious craft practice, is used to transcend limitations of memory and technique: to trace points of transition or shift. It thus reflects the liminal and conceptual territory of memory to which Markes-Young has given form in these works. As such, the series - in its effort to elude restriction or convention while representing and exploring memory - aspires to something akin to Bachelard's 'poetic expression'. 
craft + design enquiry

\section{Memory and transformation}

You have to begin to lose your memory, if only in bits and pieces, to realise that memory is what makes our lives. (Buñuel 2011: 2)

In addressing the way in which she refers to the fallibility of memory in The strange quiet of things misplaced, Markes-Young cites recent research into memory and the brain:

We've long known that the passing of time and current circumstances has a bearing on memory yet we always presumed that our recollections, at their core, were permanent. Research now indicates that memory doesn't possess these levels of accuracy and permanence, rather it is fluid and pliable - every time we remember we invent the past. (2011: 19)

The works in this series have a numerical sequence; however, there are gaps that indicate missing or incomplete works. These gaps are part of the larger, overall pattern of work. They visually inscribe a metaphorical relationship to the elusive concept of memory. Often, only fragments remain. These fragments of pseudo textile patterns are developed through mimicry, which Markes-Young describes as 'mock'-crochet, 'mock'-tatting and 'mock'-needle weaving. This description offers us an insight into her working process: a system of ongoing encounters with memory through mimetic technique. Her conceptual and physical explorations function as creative research through the catalysts of encounter and mimicry.

Markes-Young describes the significance of how her imperfect, net-like structures are read, with the fragments and imperfect patterns of this series performing the transmutability of memory:

I also like the idea of the artwork being read not just from left to right but being ambiguous as to the direction in which the narrative unfolds. The work is puzzle-like and seemingly random in its configuration, reflecting the inherent confusion when memories are challenged. (2011: 19)

The net-like structures can also be read in another way: Markes-Young, like other migrants, describes a sense of existing between past and present, of being caught between three different countries. The exploration of memory and imagination through craft practice becomes a metaphorical way of navigating the complexity of this crisis of identity. The net structure is a deceptively transparent barrier that is psychologically binding.

Freud uses a metaphor to describe memory that includes the capacity of transparency in 'layers' of memory (1961). The Mystic Writing Pad is a device developed from tablets used by early cultures, made from clay, wax or wet sand. Designed to capture temporal, drawn marks and capable of being easily erased so that a new drawing can be made, the Writing Pad is Freud's metaphor for the human mind, including perception, inception, storage and the concept of different layers of memory being formed over time. Such layers and their 
inherent permeability are reflected throughout this series of Markes-Young's. Freud suggests that there are several levels to the collection and storage of memories: the conscious, the semiconscious and the unconscious. Information withheld in the memory is largely in an unconscious space that can be drawn into consciousness, or triggered, through some associative connection (1961). For Markes-Young, this associative connection seems to be triggered through craft practice. Freud's theory explains why our memories are relative to, or evoked by, other events in time and place. This idea of the physical metaphor and the trigger of contemporaneous lived experience gives us a sense of how memories are remade and reactivated through the kind of imaginative and intuitive encounter undertaken by Markes-Young within this series.

\section{Inscribing memory in motion}

In The strange quiet of things misplaced, Markes-Young conducts a conversation with memory. She describes contemporary research into memory and the act of mining her own memory for fragments to harness within her practice. Both forms of research yield a similar result: the understanding that memory is fallible and intangible, illusory and constantly subject to reconfiguration.

Markes-Young mimics traditional textile techniques in a dialogue between memory and making, and attempts to re-engage with the site of that remembered experience of traditional Polish needlecraft, as though her child-mind had carefully traced each line. These pieces masquerade as needlecraft; they mimic twining, needle-weaving, crochet and knotting. Markes-Young appears to use these 'mock' techniques for their ability to enact the provisional capacity of drawing to transform line. These pieces, and the acts of making they reflect, are quiet and gestural. The elaborate 'mock' techniques and faux-pattern work seem to operate as a form of transformational encounter between memory, and both concept and method: an almost-silent discussion between self, work and memory. The resulting work 'performs' this transformational encounter, bringing nets, disrupted patterns and the fragmented and fluid nature of memory into the same conceptual space. It is this transformation made visible that links material, craft and memory so deftly within this series.

\section{Memory and memoir}

Memory is both subtle and inherently fallible, inevitably undergoing transformation. Each work in the series may be read as pages in an open book, or as an alternative kind of memoir, for its 'pages' follow the sequence of Markes-Young's memories of traditional textiles from her childhood. An alternative memoir, it must encompass not only the possibilities and limitations of memory as conceptual territory, but also the cultural margins of the artist's multiple migrations. Markes-Young has described her experience of migration 
as a kind of 'enforced isolation', ${ }^{1}$ an acknowledgement of the direct implications of misplaced cultural and linguistic identity. Within the pattern of this series, she navigates such complexities through making: engaging in an alternative kind of dialogue. In this way, the work enacts Barrett's performative paradigm (2010: 118). It does this through its encounter with memory, through the use of drawing as a performative practice in which mark-making operates as a trace, and through the poetic and transformative potential of craft practice and its physical materials.

Memory, in relation to contemporary visual art practice, has been linked by Joan Gibbons with the convention of autobiography: a mirror-like, raw exposure of personal 'experience', or perhaps a confessional (2007: 9-28). Markes-Young's approach seems to resist this. Instead, her practice could be described as an oblique form of memoir, akin to Drusilla Modjeska's proposal that, 'we think of memoir as the mapping of a mind rather than (or as well as) the recreation of experience' (2002: 196). A model such as Modjeska's operates in opposition to the more visceral autobiographical projects of artists like Tracey Emin, which, in the words of Gibbons, act as a form of 'externalisation of personal memory' (2007: 9-28). For Markes-Young, accessing memory through the practice of craft is a performative practice. Rather than autobiography, her craft is an act of engaging with or encountering memory. As Modjeska points out, the relationship between memory and autobiography is never straightforward. It is not 'the simple evacuation of the forgotten or repressed', but instead, 'it [memory] is complexified by a conflation of the past and present' (2002: 196).

There is a sense of flux in Markes-Young's imperfect works, where gesture and movement are constantly at play through both the slow building-up of repetitive pattern and its disintegration. In her works, the ratio of wear is as important as the construction of the web-like layers, if not more so. This duality inscribes in the work a sense of both the entropic and the poetic qualities of memory.

The need to look closely at Markes-Young's work in The strange quiet of things misplaced draws the viewer in, making it operate as an aesthetic and conceptual net. The gestures visible within this work express sensitive nuances that are measured and carefully drawn and tensioned. Memory operates as a poetic tool for making, performing the role of both catalyst and lens. Memory is drawn in thread, using imperfect pattern structures that encapsulate thread's unique capacity to twist and spin, to ply and knot, to weave a web. Intersections and linkages are at once strong and weak, held in place by the tension of interlacing. Some elements of these works are only partially visible, or visible in certain lights, as, for example in The strange quiet of things misplaced \#27, \#33 and \#30. In these works, the light is like another metaphor for memory: dappled, diffused, sharp, but never still or fixed. Rowley describes the confluence between 'pastpresent', which 'becomes part of the necessity, not the nostalgia, of living' (2012). This seems an apt illustration for Markes-Young's compulsion to attend to and engage with memory through her work.

1 E. Markes-Young, 2013, personal communication, June. 
Drawing attempts to capture the transience of memory, thus it becomes a poetic device that performs that set of fleeting nuances in a focused attempt to reclaim, re-see or reactivate the site of memory. Modjeska considers that, with the construction of memoir, 'the question isn't so much one of truth to a narrative that exists outside the text as of fidelity to the creative process' (2002: 196). She suggests that the importance lies with the way in which the materials or memory are articulated. For Markes-Young, this means that memory is observed as a threshold state where invention, speculation and fabrication occur alongside, and in response to, retrieval. It is the fluidity of that encounter that she attempts to transcribe within this series. As Modjeska observes, 'discovery and invention can live very close to each other' (2002: 196). Markes-Young's work is motivated by the dynamic slippages and integral transformation at the heart of retrieval. It is this elusive space between discovery and invention that resonates within The strange quiet of things misplaced.

\section{Craft, transformation and navigation}

Craft - verb (t) 9. to make or manufacture (an object, etc.) with skill and dexterity. (Macquarie Dictionary 2005)

If we consider 'craft' as a verb, it relates to the act of crafting something, or making with dexterity and skill. Can this definition apply to The strange quiet of things misplaced, in which Markes-Young mimics traditional needlecraft? This faux needlecraft is used as a drawing method to provide an encounter with personal memory, the resulting work 'performing' and enacting the concept of memory. This discussion proposes that when craft practices are employed in this subversive way, they can be described as a type of poetic device. Within The strange quiet of things misplaced Markes-Young's detailed works become imperfect maps for the tracing of memory's elusive threads, knots and gaps: and while she encounters and attends to her memory, a subtle catalyst for transformation is found.

While the foundation of Markes-Young's work is an ongoing encounter between the artist and her memory, there is also, perhaps, evidence of active participation or elaboration by the maker. Rowley, in the context of craft and storytelling, suggests that 'the rhythms of making ... are the heart-beats of human sociability' and that, furthermore, 'the temporalities of craft are somehow bound up with those of the human body' (2012: 234). It seems that in Markes-Young's series, the crisscrossing of temporal space is given physical form not only in the works themselves, but in the process by which they're created: the time, the detail, the active and close attention that needs to be paid to their making. The physical 'crafting' of the works offers a powerful echo of the constant transformation of the concept and site of memory that Markes-Young explores. That a physical act of crafting can provide a tangible, perhaps even inseparable, framework for conceptual realities offers a potent tool for reading Markes-Young's series. For, as Victoria Mitchell explains, 'Making and speaking ... are both primarily tactile and 
sensory ... through the senses, touching and utterance share common origins in the neural system' (2012: 161). Enunciation, therefore, through the encounter of craft practice, activates thought and transforms memory. Markes-Young's work may, then, be viewed as both a physiological and psychological encounter with memory and the gesture of making as an utterance of that encounter. The description of a relationship between sensorial and speculative awareness also offers another explanation as to why Markes-Young's conceptual and material accounts of her work are inseparable.

During the conceptual and material construction of this series, Markes-Young appears to have followed a personal and unique set of navigational tools. Such a process may require, as Bal discusses, a kind of circumnavigation, or following of the object's 'signs' during the research process (2008: 206). This indicates the need for a receptive or open approach, a readiness to consider a material or idea from multiple angles. For Markes-Young, it is the unknown that links concept and material practice: the physical encounter with material practice that allows for the conceptual leap to occur, and something of the unknown to be revealed. Sometimes this kind of strategy is most resonant when the pattern is not known in advance - not charted or navigated. A certain willingness to allow the project to unfold, to follow its direction, to pay close attention, is useful.

While there may be a shape, a sense, the intuitive work must essentially be done at the site of making to enable transformation. Ideally, this process of working-out should remain fluid, intuitive, responsive to encounter and nuance and should, overall, be provisional. In its capacity to draw together mimicked, 'invented' processes that evolve and respond to the shifting conceptual grounds of memory, The strange quiet of things misplaced can be seen to employ craft as a transformative device capable of performing physically, conceptually and poetically the provisional and serendipitous nature of memory.

\section{Drawing: Casting a net}

Anita Taylor considers drawing to be:

propositional, preparatory, visionary, imaginative, associative, factual, generative, transformative or performative. (2008: 9-11)

Throughout this series, Markes-Young appears to employ textile material and craft practices as a form of drawing because of their unique capacity for performing the propositional and the provisional in the various ways that Taylor describes. The works lend themselves to a clear challenge of defined notions of what the practice of 'drawing' may encompass or accomplish. In addition, it seems that the inherent mimicry of needlecraft techniques in the series allows for a provisional, intuitive, inventive and innovative approach to craft practice as a type of 'performative' drawing. 


\section{Pattern and entropy}

The use of entropic or disintegrating pattern is integral to the capacity of these works of Markes-Young's to articulate the elusive qualities of memory. Initially, these patterns are deceptive. At first glance, they resemble items of found domestic textile craft, but all elements are in fact made by hand and no found textile objects are used. The patterns appear to comply with conventions of traditional needlecraft, but they in fact only mimic them. In fact, the patterns are not regular or symmetrical: they are disrupted and ultimately entropic, visually describing the perceptual breakdown and absences of memory.

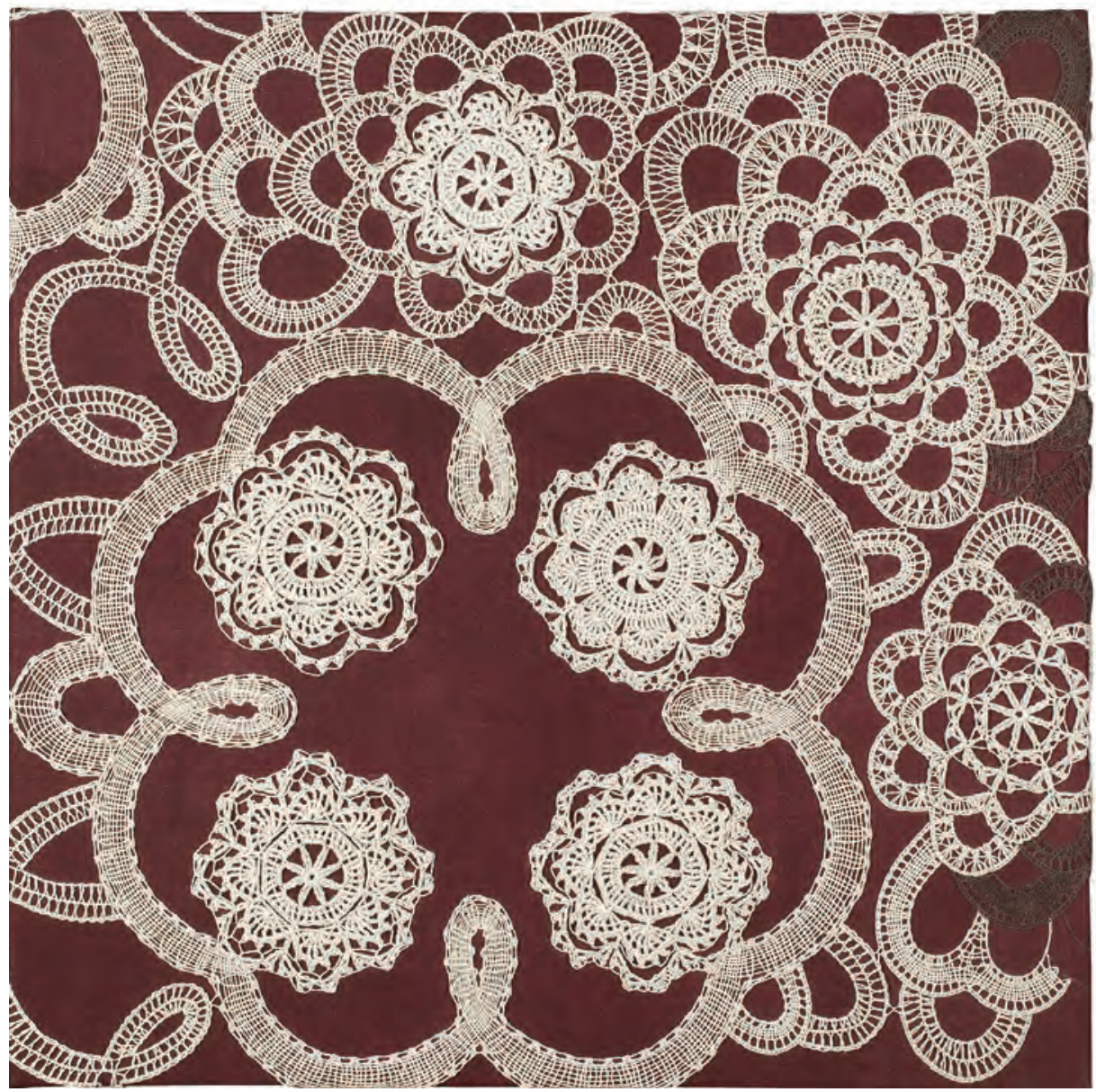

Figure 8. Elisa Markes-Young, The strange quiet of things misplaced \#37, 2011, acrylic, pencil, wool, cotton and silk on Belgian linen, seven panels, various sizes

Photo: Christopher Young. Licensed by VISCOPY Australia

The patterns are vital elements of the work, but not because of the deception they imply, for this is simply a type of camouflage. Instead, they 'perform' 
the subject of the work, the shifting territory of memory. The net-like patterns encounter entropic disruptions, operating as an intuitive and innovative drawing method, and enacting a poetic approach to visual interpretation. MarkesYoung's patterns can be seen to act as a model for the way in which memory sits outside conventions of autobiographical or logical narrative.

Markes-Young describes her intention with the disintegrating patterns as follows:

With this piece, The strange quiet of things misplaced \#37, I'm particularly interested in the layering of patterns over each other and how this affects the perception of individual elements. Areas of shadow repeat and emphasise the play of positive and negative space whilst also drawing attention to the disintegrating patterns and their reappearance elsewhere on the canvas, changed. I'm fascinated by this distortion and the progression towards it. (2011: 19)

Pattern can be perceived as a device in craft practice. Jane Graves argues that pattern has been fundamental to design history and rational ideology (2012: 116). She proposes an alternative dual reading of pattern as both positive and negative where 'pattern eludes, evades, and troubles our gaze' (2012: 121). Such an alternative dual reading speaks of Markes-Young's ability to both build up and break down patterns in The strange quiet of things misplaced \#37, engaging attention through discomfort or the unexpected. As the patterns within the works both employ and disregard expectation and tradition, the viewer is drawn in and then challenged.

Roger Caillois defines the concept of entropy as a 'dissymmetry': a breakdown that moves in one direction, where entropy operates as a type of erosion. This is linked to his description of a 'boundary condition' achieved through a process of mimicry. Caillois describes how insects who camouflage themselves through mimicry in the natural environment may enter a psychotic state where they can no longer distinguish the boundary between themselves and the surrounding environment. Further, as cited by Alain-Bois and Krauss, Caillois links this to a psychological condition experienced by 'schizophrenics who feel themselves dispossessed ... by the space around them': where their sense of self and personal identity becomes disrupted (cited in Bois \& Krauss 1996: pp. 39-40).

These perceptions of a transformational state can be useful in reading aspects of Markes-Young's series. Markes-Young reports how an inability to feel a sense of belonging within a new cultural space propels her to examine her memories. Entropy, through the breakdown or erosion of pattern becomes a physical and psychological tool to address both the disconnected sense of self and the ambiguity of memory. Further, it can be perceived in relation to the pursuit of a compulsive practice and Markes-Young's descriptions of the lived experience of multiple immigrations. For Markes-Young's series, as an encounter and reencounter with personal memory and identity, compulsively performed through a reflexive craft-based practice, such a concept could be read as camouflage: a psychological strategy related to the ongoing construction of personal identity as a migrant. Rowley's reminder that 'craft ... and performance become intricately 
bound up in our sense of identity, our understanding of the past' (1997: 76), emphasises our awareness of Markes-Young's dealings with her own identity through this series.

Markes-Young's series reflects again and again the capacity of entropic patterns to mimic the incomplete, cyclic, and open-ended nature of memory. Of her use of patterning in this body of work, she says:

they were chosen for their potential to be built out, transformed, completed and complemented with other motifs and techniques or broken up or unravelled until they became another pattern. ${ }^{2}$

Far from being mere adornment, these patterns, together with their unexpected disruptions, form the genus of the work, seeming to drive both concept and practice and the urge towards the poetic. The performative capacity of patternmaking and their heterogeneous deviations enact the sense of what is known, what is unknown, what is yet to be known and what will remain unknowable about memory.

David Brett's descriptions of how textile structures emerge and patterns evolve provide an insight into the intuitive development of Markes-Young's works. As Brett suggests, the process and crafting of cloth and fibres 'is itself a generator of more or less complex forms and structures' (2012: 2). The works in this series, with their complex incorporation of patterns done and undone, created and then subverted, are each created from small, simple, repetitive process. The hand-stitching and 'invented' or 'imagined' embroidery techniques represent both intricacy and concentrated focus, together with the most humble manual engagement: the needle, the thread, the hand. They are, as Brett reflects, both 'the most manual and the most abstract' (2012: 2).

In Markes-Young's work, the intuitive and mimetic aspects of her craft practice allow the instability of memory to be presented through pattern and entropy. Entropy is present in these works which are constructed from a process of 'drawing': 'playing with pattern and randomness, giving testimony to the entropy inherent in "nature"' (K. Hayles, cited in Langhill 2002: 27). Through the fusion of the grid and the material on Markes-Young's stretched canvas, an entropic entity is created: order and disorder, reminiscent of the instability of personal identity and memory, residing side by side.

\section{Conclusion}

Markes-Young suggests that it is a mistake to objectify memory as a form of metaphorical shelter: a safe space into which it may be possible to psychologically retreat, for memory is not solid. Instead, it is shifting, intuitive

2 Markes-Young, 2013, personal communication, June. 
and possibly, as Freud suggests, at least partially transparent (1961: 229). The performative 'act' of craft both activates and transforms memory and offers a dynamic tool for creative research in material practice.

As the ultimate poetic device, for Markes-Young, memory serves as a tool for both thinking and making. The artist considers her personal memories despite, and perhaps in part because of, their enigmatic qualities in representing a sense of home. This discussion has focused on a provisional exploration of how this work may be read. It considers Markes-Young's belief in memory as elusive, shifting and flawed. It observes how the work is able to 'perform' the encounter with memory through material and craft practice. This understanding of memory as a poetic rather than a practical rational device evolved in response to a complex personal cross-cultural history, of that threshold space of the immigrant, of the gap between departure and arrival. It has also evolved, however, through the encounter with practice, or the performative endeavour of craft. The poetic occurs here because, although Markes-Young's work requires the labour of needlecraft, it frees itself from accepted conventions through mimicry, imagination and entropy. The dynamic of Markes-Young's work remains as elusive and ambiguous as its subject matter: and therein lies the intrigue.

Belinda von Mengersen is an artist and academic specialising in textiles. She studied textiles at Goldsmiths College, University of London then completed a PhD at the University of Newcastle, Australia. She is lecturer in Technology (Textiles) at the Australian Catholic University, Sydney.

\section{References}

Bachelard, G. 1998, Air and Dreams: An Essay on the Imagination of Movement, E. Farrell \& C. Farrell (trans), Dallas Institute Publications, pp. 5, 10.

Bal, M. 2008, 'Research practice: New words on cold cases', in M. Holy \& M. Smith (ed.) What is Research in the Visual Arts? Obsession, Archive, Encounter, Massachusetts: Sterling and Francis Clarke Art Institute, p. 206.

Barrett, E. 2010, Kristeva Reframed, London: I.B. Tauris, p. 118.

Bois, Y. \& Krauss, R. 1996, 'A users guide to entropy', October, vol. 78, pp. 39-88.

Brett, D. 2012, 'Rethinking decoration: Pleasure \& ideology in the visual arts' (2005), in C. Harper (ed.) Textiles: Critical and Primary Sources, vol. 4, Identity, pp. 1-8.

Buñuel, L. 2011, My Last Breath, London: Random House, p. 2.

Freud, S. 1961 (1923-1925), 'A note upon the Mystic Writing Pad', The Ego and The Id and Other Works, vol. 19, London: The Hogarth Press, pp. 227-32. 
Gibbons, J. 2007, Contemporary Art and Memory: Images of Recollection and Remembrance, London: I.B. Tauris, pp. 9-28.

Graves, J. 2012, 'Symbol, pattern and the unconscious: The search for meaning' (2002), in C. Harper (ed.) Textiles: Critical and Primary Sources, vol. 4, Identity, p. 116.

Langhill, C. 2002, essay in Dorothy Caldwell: Field Notes, exhibition catalogue, Toronto: Textile Museum of Canada, p. 27.

Lehrer, J. 2007, Proust Was a Neuroscientist, Boston \& New York: Houghton Mifflin, pp. 75-95.

Modjeska, D. 2002, Timepieces, Australia: Picador, p. 196.

Markes-Young, E. 2011, 'Artist's statement', in Patrick Snelling (ed. \& curator), Sensorial Loop: 1st Tamworth Textile Triennial, 2011-2013, exhibition catalogue, Tamworth Regional Gallery, p. 19.

- - 2013, The Strange Quiet of Things Misplaced, Perth: Zebra Factory.

Mitchell, V. 2012, 'Textiles, text and techne' (1997), in C. Harper (ed.) Textiles: Critical and Primary Sources, vol. 4, Identity, p. 159-68.

Onians, R. 1951, The Origins of European Thought, New York: Arno Press, pp. 13-14; 67-68.

Rowley, S. 1997, 'Craft, narrative and representation', in S. Rowley (ed.), Craft and Contemporary Theory, Sydney: Allen \& Unwin, pp. 76-84.

- - (ed.) 2012, 'Craft, creativity and critical practice' (1999), in C. Harper (ed.) Textiles: Critical and Primary Sources, vol. 2, Production, p. 223-39.

Taylor, A. 2008, 'Re: positioning drawing' in S. Garner (ed.), Writing on Drawing, Bristol: Intellect, pp. 9-11. 
This text taken from craft + design enquiry issue 6, 2014, Craft.Material. Memory, Edited by Anne Brennan and Patsy Hely, published 2014 by ANU Press, The Australian National University,

Canberra, Australia. 